Desmond Norris MD, Andrew Klahsen MD, Brian Milne MD FRCP(C)

\title{
Delayed bilateral spinal anaesthesia following interscalene brachial plexus block
}

Purpose: To present a case of delayed neuraxial blockade after interscalene brachial plexus block.

Clinical features: A 65-yr-old lady presenting for radial head excision underwent a right interscalene block using bupivacaine and lidocaine. She experienced excellent anaesthesia and had stable vital signs for the duration of surgery. However, after $65 \mathrm{~min}$, she developed signs of bilateral neuraxial block, progressing over the following hour to involve the cervical to lumbar dermatomes, with sparing of the phrenic nerves. The patient remained alert and communicative throughout with haemodynamic stability. Two days following the block, the patient experienced severe frontal and occipital pain, typical of a post dural puncture headache, which responded to fluids and recumbency.

Conclusion: This example of delayed central neural blockade complicating interscalene block is presented in contrast to other reports, which have usually occurred promptly after injection, accompanied by complete sensory and motor block requiring cardio-respiratory support. The presumed mechanism of the delayed onset of bilateral neuraxial spread was a dural cuff puncture with slow CSF spread from a plexus sheath "depot" of local anaesthetic.

Objectif: Présenter un cas de bloc médulaire consécutif à un bloc plexique interscalénique.

Caractéristiques cliniques: Un bloc plexique interscalénique à la bupivacaïne et à la lidocaïne a été administré à une femme de 65 ans programmée pour l'excision d'une tête radiale. L'anesthésie a été excellente et les signes vitaux stables pendant la chirurgie. Cependant, après $65 \mathrm{~min}$, elle a manifesté des signes bilatéraux d'anesthésie neurale centrale qui a

\section{Key words}

ANAESTHESIA, REGIONAL: interscalene; COMPLICATIONS: total spinal anaesthesia.

From the Department of Anaesthesia, Kingston General Hospital, 76 Stuart St., Kingston, Ontario K7L 2V7.

Address correspondence to: Dr. Brian Milne, Department of Anaesthesia, Kingston General Hospital, 76 Stuart St., Kingston, ON K7L 2V7.

Accepted for publication 26th October, 1995. progressé l'heure suivante jusqu'à se propager vers les dermatomes cervicaux et lombaires, sans toucher les nerfs phréniques. La patiente est demeurée alerte et hémodynamiquement stable. Deux jours après le bloc, elle sest plainte d'une céphalée frontale et occipitale considérable, typique d'une céphalée postponction dure-mérienne laquelle a régressé avec l'administration de liquides et le décubitus.

Conslusion: Un cas de bloc neural central retardé compliquant un bloc interscalénique est présenté. Cette observation differe avec d'autres qui mentionnent que cette complication survient rapidement après l'injection et s'accompagne d'un bloc sensoriel et moteur complet nécessitant un support hémodynamique. On présume que le mécanisme expliquant le retard de propagation bilatérale du bloc a été le ponction d'un manchon dure-mérien avec propagation lente du LCR à partir d'un dépôt d'anesthésique local dans la gaine plexique.

Since its description by Winnie, ${ }^{1}$ interscalene brachial plexus block has been extensively used for surgery involving the upper limb. ${ }^{2}$ Complications include total spinal anaesthesia, ${ }^{3}$ bilateral epidural blockade ${ }^{4}$ and bilateral block without epidural or subarachnoid spread. ${ }^{5}$ Other complications reported include permanent neurological damage to motor outflow from the brachial plexus, ${ }_{2}^{5}$ hoarseness, Horner's syndrome, ${ }^{6}$ cardiac arrest ${ }^{7}$ and phrenic nerve palsy. We report a case of delayed onset, widespread bilateral anaesthesia without loss of consciousness and without major cardiorespiratory compromise following an interscalene block.

\section{Case report}

A 65 -yr-old lady (weight $65 \mathrm{~kg}$, height $165 \mathrm{~cm}$ ) of average build, with long-standing osteoarthritis was booked for elective removal of her right radial head under brachial plexus block.

Past history included severe nausea and vomiting following general anaesthesia and anaphylactoid reactions to morphine and codeine. Medications included ibuprofen for pain relief.

Examination showed BP 140/70, HR 80, regular and $\mathrm{SpO}_{2} 96 \%$ breathing room air. 
After NIBP, ECG and oxygen saturation monitors were applied, with propofol sedation $\left(35 \mu \mathrm{g} \cdot \mathrm{kg}^{-1} \cdot \mathrm{min}^{-1}\right)$ and with sterile technique, a right interscalene block was established according to the method described by Katz. ${ }^{8}$ A 22 gauge blunt bevel block needle was used, with paraesthesiae sought in the interscalene groove at the $\mathrm{C}_{6}$ level. The needle direction was at right angles to the skin over the interscalene groove (inward, and slightly dorsad and caudad). The first puncture (depth $3 \mathrm{~cm}$ ) failed to produce the desired paraesthesiae (no aspiration attempted at this site), and a second puncture was made $0.5 \mathrm{~cm}$ anterior to the first, where right lateral forearm paraesthesiae were obtained at a depth two centimetres. Thirty millilitres of a mixture of equal parts bupivacaine $0.5 \%$ and lidocaine $2 \%$ (carbonated) were injected slowly, with initial and repeated negative aspiration for blood or CSF. On initial injection, the patient complained of a brief paraesthesia in the contralateral arm. Injection was paused at this point. Since there was no obvious motor or sensory deficit, and since the paraesthesia rapidly disappeared, it was decided that the patient's subjective complaint was caused by a noninvasive blood pressure cycle. At $12 \mathrm{~min}$ after injection, surgical incision over the radial head was possible, and no reports of pain were elicited except for "aching" during bone excision.

During the surgical procedure, the patient was alert and talkative with stable vital signs, $\mathrm{SpO}_{2}$ was $98 \%$ and no further motor or sensory changes were noted or reported.

Postoperatively, $50 \mathrm{~min}$ after injection, the patient assisted with her transfer from the OR table to the transport stretcher. Initial recovery room status showed a right motor and sensory block extending from $\mathrm{C}_{4}$ to $\mathrm{C}_{8}$.

At $65 \mathrm{~min}$, left grip strength was markedly reduced. At $80 \mathrm{~min}$, the patient complained of "heaviness and numbness" of the occiput, and was unable to lift her head off the pillow. Examination showed a complete and dense bilateral motor and sensory block extending from $\mathrm{C}_{2}$ to $\mathrm{T}_{4}$, determined by absence of limb motor function and sensory loss to pin prick. The only exception was left thumb flexion and left $\mathrm{C}_{6}$ dermatome sensation. Vital signs were BP 100/60, HR 56, RR 12 , $\mathrm{SpO}_{2} 96 \%$ with oxygen at $3 \mathrm{~L} \cdot \mathrm{min}^{-1}$ via nasal prongs. At $110 \mathrm{~min}$, anaesthesia had spread downwards to $\mathrm{L}_{5}$ (preserved plantar flexion and sacral dermatomes). During this entire period, the patient's cardiorespiratory status remained unchanged. At $260 \mathrm{~min}$, motor blockade and sensory anaesthesia had regressed to involve the right $C_{5}$ to $T_{3}$ distribution only. The patient was admitted for observation overnight and discharged the next day.

The patient was readmitted $40 \mathrm{hr}$ after interscalene block with a severe, postural, bilateral occipital and frontal headache, which responded to fluids and recumbency over $72 \mathrm{hr}$. A CT scan of the head was negative. The presumptive diagnosis was post dural puncture headache. She was discharged three days later with resolving symptoms. Follow up at ten days was unremarkable.

\section{Discussion}

This case clearly demonstrates central neural blockade after interscalene brachial plexus block. The classic features of the ensuing headache strongly suggest that dural puncture had occurred. If so, intrathecal spread would be the logical explanation of the neuraxial block. If that is the case, four features are noteworthy. First, the onset of the neuraxial block was considerably delayed. Other reports of unintentional neuraxial blockade in this context are characterized by rapid onset of symptoms. ${ }^{3,9,10}$ Secondly, severe cardiorespiratory compromise necessitating tracheal intubation and pulmonary ventilation did not occur, in contrast with other reports. ${ }^{3,4,9,10}$ Thirdly, the lack of overt spread to nearby brain stem in light of the spread to lumbar dermatomes is puzzling. Fourthly, the contralateral paraesthesiae on initial injection, if important, are unexplained by intrathecal spread.

The presumed mechanism of delayed onset of neuraxial block is as follows: the first, somewhat posterior, needle puncture pierced the dural cuff of the $C_{6}$ root, opening a portal of entry into CSF. A "normal" brachial plexus block resulted from the second needle placement, following which the depot of local anaesthetic in the plexus sheath slowly leaked into the subarachnoid space. Once in the CSF, the local anaesthetics were spread, aided by patient movement and CSF circulation.

At least three anatomically based explanations of spread of local anaesthetics complicating brachial plexus block have been proposed by others. ${ }^{1}$ The block needle may penetrate the intervertebral foramen, the local anaesthetic then gaining direct access to the intrathecal space. This would appear possible only with the interscalene approach to the brachial plexus, and only if the needle were direct horizontally. Such needle direction was carefully avoided in our case. Alternatively, long dural cuffs have been found in autopsy studies, extending as far as $8 \mathrm{~cm}$ beyond the intervertebral foramen. ${ }^{1}$ In this scenario, it would be possible to perform a direct intrathecal injection even with an appropriately directed needle. Finally, it is possible that intraneural injections can find their way into the subarachnoid space. It has been shown by $x$-ray studies that solutions injected subepineurally may spread centrally to the spinal cord. The presumed explanation is that the epineurium of a peripheral nerve is a 
continuation of the pia mater. ${ }^{1}$ Moore suggested that the time required for penetration of the pia might explain those cases of delayed high spinal block. ${ }^{11}$

\section{Conclusion}

We report an unusual case of delayed onset of adverse effects after an interscalene brachial plexus block. Our report makes clear the importance of the mechanics of depth and direction of needle placement with interscalene block and of continued patient monitoring and access to resuscitation equipment following brachial plexus blocks.

\section{References}

1 Winnie AP. Plexus Anesthesia. Philadelphia: WB Saunders, 1983: 167-80.

2 Winnie AP. Interscalene brachial plexus block. Anesth Analg 1970; 49: 455-66.

3 Ross $S$, Scarborough CD. Total spinal anaesthesia following brachial-plexus block. Anesthesiology 1973; 39: 458.

4 Kumar A, Battit GE, Froese AB, Long MC. Bilateral cervical and thoracic epidural blockade complicating interscalene brachial plexus block: report of two cases. Anesthesiology 1971; 35: 650-2

5 Barutell $C$, Vidal $F$, Raich $M$, Montero A. A neurological complication following interscalene brachial plexus block. Anaesthesia 1980; 35: 365-7.

6 Seltzer JL. Hoarseness and Horner's Syndrome after interscalene brachial plexus block. Anesth Analg 1977; 56: 585-6.

7 Edde RR, Deutsch $S$. Cardiac arrest after interscalene brachial-plexus block. Anesth Analg 1977; 56: 446-7.

$8 \mathrm{Katz}$ J. Atlas of Regional Anaesthesia, 2nd ed. Norwalk: Appleton \& Lange, 1948: 63-5.

9 Baraka A, Hanna M, Hammoud R. Unconsciousness and apnoea complicating parascalene brachial plexus block: possible subarachnoid block. Anesthesiology 1992; 77: 1046-7.

10 Dutton RP, Eckhardt WF III, Sunder N. Total spinal anaesthesia after interscalene blockade of the brachial plexus. Anesthesiology 1994; 80: 939-41.

11 Moore DC, Hain RF, Ward A, Bridenbaugh LD. Importance of the perineural spaces in nerve blocking. JAMA 1954; 156: 1050-3. 